\title{
Improving decision making, communication and documentation regarding advance resuscitation decisions in a tertiary care hospital in Sri Lanka
}

Shenal Appuhamy ( $\nabla$ shenal.appuhamy@gmail.com )

National Hospital of Sri Lanka https://orcid.org/0000-0002-9615-5394

Dinusha Hewage

National Hospital of Sri Lanka

Research Article

Keywords: decisions, resuscitation, advance, intervention, patient, period, doctors

Posted Date: August 17th, 2021

DOl: https://doi.org/10.21203/rs.3.rs-799205/v1

License: (1) This work is licensed under a Creative Commons Attribution 4.0 International License. Read Full License 


\section{Abstract \\ BACKGROUND}

Resuscitation decisions made in advance are especially important to prevent negative patient outcomes at end-of-life. We conducted a clinical audit to assess the current practice of these decisions in Sri Lanka and then introduced interventions to improve the same.

\section{MATERIALS AND METHODS}

An auditor-administered questionnaire developed through a focused group discussion among experts was used to analyze the medical records of deaths during a period of sixty days focusing on advance resuscitation decisions and factors affecting them. The junior doctors directly involved in the care of each patient were interviewed regarding their retrospective judgement about the most appropriate resuscitation decision, which was later compared with the decision of an expert panel, who decided on the most appropriate resuscitation decision based on the medical records of the patient. An educational session for doctors was then conducted to improve their knowledge about advance resuscitation decisions including the importance of meticulous documentation of such decisions. The outcome was assessed after sixty days following the introduction of the intervention using the same questionnaire.

\section{RESULTS}

There was a significant improvement in the number of documented advance resuscitation decisions from $4 / 40(10 \%)$ to $17 / 38(44.73 \%)(Z=3.5, P=0.0006)$, with a significant increase in DNACPR decisions from $4 / 40(10 \%)$ to $14 / 38(36.8 \%)(Z=2.8, P=0.005)$ following the intervention. Unsuccessful CPR attempts decreased significantly from $31 / 40(77.5 \%)$ to $14 / 38(36.8 \%)(Z=3.6, P=0.0003)$ in the post-intervention period. The resuscitation decisions suggested by junior doctors that matched with expert decision increased significantly for both interns ((from $11 / 40(27.5 \%)$ to $22 / 38(57.9 \%)(Z=2.7, P=0.0066)$ ) and registrars $((18 / 40(45 \%)$ to $27 / 38(71.05 \%)(Z=2.3, P=0.0202))$ in the post-intervention period.

\section{CONCLUSION}

Documentation and practice regarding advance resuscitation decisions is suboptimal in Sri Lanka. This can be improved by interventions targeting improving the knowledge about the concept and its proper documentation among health care professionals.

\section{Introduction}

Cardiopulmonary Resuscitation (CPR) is the act of reviving someone from cardio- respiratory arrest using a sequence of actions including chest compressions and lung ventilation. Since the concept was first 
formally described in 1960(1), modern CPR has evolved rapidly as an important treatment option and was used as the 'default' resuscitation strategy for a few decades. However survival to discharge following inhospital cardiac arrest is still very low(2) and there is little improvement in this trend over the past two decades despite scientific research, ongoing clinician training and guidance(3). One of the main reasons for this is use of CPR in the inappropriate setting.

CPR used in the wrong setting can lead to poor patient outcomes(4). Failed CPR can lead to physical suffering to the patient and harm to their dignity at the time of their death. Even when successful, residual adverse effects of permanent neurological disability, lung contusions, rib and sternal fractures can impair the quality of life in survivors(5). This emphasizes the need to adopt an alternative strategy than resuscitating all cases of cardiopulmonary arrest.

The concept of not offering CPR to certain patients at the discretion of the clinician and/ or the patient was formally incorporated into clinical practice since 1970's(6). Since then, the concept has evolved amidst the numerous controversies around it. It is commonly practiced in developed countries.

Sri Lanka is a low middle income Asian country with health indices closely matching those of developed countries(7). Unfortunately, palliative and end-of-life care is poorly developed and advance resuscitation decisions are uncommon in Sri Lanka for a variety of reasons(8). Some of these include inadequate knowledge about the concept among health care professionals(9), cultural beliefs(10) and possibly poor public awareness about the concept.

We conducted an audit to find out the current practice about advance resuscitation decisions and then carried out interventions to improve the same. A re-audit was conducted later to measure the sustainability of our interventions.

\section{Materials And Methods}

This retrospective audit was conducted in two general medical wards in the National Hospital of Sri Lanka. The male and female wards of professorial medical unit were selected for the purpose. Each ward has 55 allocated bed spaces. Firstly, we obtained permission from the clinical director of professorial medical unit and the deputy director of the National Hospital of Sri Lanka to access patient records. Ethical clearance was obtained from ethics review of University of Colombo. Then we developed a questionnaire to analyze the documentation of resuscitation decisions on every death that occurred within the audit period (Annex 1). This was developed through a focused group discussion which included several senior clinicians with expertise in end-of-life care, namely two senior professors in clinical medicine, a physician with special interest in end-of-life care and a physician with special interest in geriatric medicine. Since there are no guidelines about resuscitation decisions in Sri Lanka at the time of writing, recommendations from the revised guidelines issued by the British Medical Association, The Resuscitation Council (UK) and the Royal College of Nursing in 2016 regarding 'Decisions relating to cardiopulmonary resuscitation'(11) were used as the standard of care. The questionnaire (Annexure 1) was based on the above guidelines. The 
questionnaire was tested on 15 deaths from a different general medical ward in the national hospital of Sri Lanka to ascertain its validity and several changes were made to avoid practical difficulties of use.

The audit period was sixty days backwards from 09th April 2021. All the medical records of each patient who died during the audit period was thoroughly analyzed by a panel of experts comprising of two consultant physicians and a family physician with expertise in medical ethics. The discussion and retrieval of medical records was coordinated by two research assistants. The panel of experts then retrospectively decided on the most appropriate resuscitation decision for each patient, based on the guideline recommendations. Then the junior doctors who were directly involved in the care of the patient were contacted, and those who consented were interviewed to assess their professional opinion about the appropriate resuscitation decision in each case. This decision was then compared with the professional opinion of the expert panel.

At the end of the sixty-day audit period, we conducted an education session with the participation of 18 doctors in ward service in the two selected wards. This was done on 10th April 2021 in the form of a lecture series about advance resuscitation decisions delivered in two sessions (Annexure 2). On the same day, a pre-printed form was introduced (Annexure 3) to document the goals of care for each patient at risk of death during the index ward stay. This form required to be filled on admission and then incorporated into the medical records. The results of the interventions were reassessed by analyzing the deaths that occurred during a sixty-day period starting from 11st March 2021. Data analysis was done through SPSS ${ }^{8}$ version 25.0 .

\section{Results}

The total of 78 deaths was found during the period from 12/02/2021 to 09/06/2021 with 42 males (53.8\%) and 36 females (46.2\%). Effects of COVID-19 pandemic meant that the male ward had to be relocated at a different building of the national hospital. All patients who died were above 16 years of age, except for one 14-year-old girl. Further baseline characteristics are given in Table 1. 
Table 1

BASELINE CHARACTERISTICS OF PATIENTS ON ADMISSION TO THE GENERAL MEDICAL WARD

\begin{tabular}{|llll|}
\hline Sex & Male & $\begin{array}{l}\text { Pre intervention } \\
\text { period }\end{array}$ & $\begin{array}{l}\text { Post- intervention } \\
\text { period }\end{array}$ \\
\cline { 2 - 4 } & Female & $26(65 \%)$ & $24(63.2 \%)$ \\
\hline Age (mean) & $14(35 \%)$ & $14(36.8 \%)$ \\
\hline Number of cormorbidities & 0 & 62.7 & 59.8 \\
& 1 & 0 & $2(5.3 \%)$ \\
\hline 2 & $15(37.5 \%)$ & $11(28.9 \%)$ \\
\hline $\begin{array}{l}\text { Number of people with a previous resuscitation decision/ } \\
\text { advance health directive }\end{array}$ & 0 & $12(30 \%)$ & $14(36.8 \%)$ \\
\hline & 4 & $10(25 \%)$ & $8(21.1 \%)$ \\
\hline
\end{tabular}

Neither group had participants who had contraindications to CPR, with documented discussions indicating the patient did not wish to be resuscitated in the event of cardio-pulmonary arrest regardless of clinical appropriateness or with patients who had valid advanced resuscitation plans.

Out of the studied cases, only $4 / 40(10 \%)$ in the pre-intervention group had a clearly documented resuscitation decision compared to $17 / 38(44.7 \%)$ in the post- intervention group. 13/38 (34.2\%) patients in the post-intervention group had the Goals-of-care form filled on admission. CPR had been performed without success in $31 / 40(77.5 \%)$ patients in the pre- intervention group compared to $14 / 38(36.8 \%)$ in the post- intervention group. Interestingly $3 / 4(75 \%)$ of patients the pre-intervention group and $8 / 14(57.14 \%)$ in the post- intervention group had CPR performed on them when there was a clearly documented decision not to do so. Results of the other factors comparatively analyzed during the two periods are summarized in Table 2. 
Table 2

FACTORS ASSESSED WHEN A VALID RESUSCITATION DECISION HAS BEEN DOCUMENTED

\begin{tabular}{|c|c|c|c|c|c|}
\hline & & \multicolumn{2}{|c|}{$\begin{array}{l}\text { Pre- } \\
\text { intervention }\end{array}$} & \multicolumn{2}{|c|}{$\begin{array}{l}\text { Post- } \\
\text { intervention }\end{array}$} \\
\hline & & $\mathrm{N}$ & $\begin{array}{l}\text { Valid } \\
\text { percent }\end{array}$ & $\mathrm{N}$ & $\begin{array}{l}\text { Valid } \\
\text { percent }\end{array}$ \\
\hline \multirow[t]{3}{*}{ WHO MADE THE RESUSCITATION DECISION } & CONSULTANT & 4 & $100 \%$ & 5 & $35.71 \%$ \\
\hline & $\begin{array}{l}\text { SENIOR } \\
\text { REGISTRAR }\end{array}$ & 0 & 0 & 9 & $64.29 \%$ \\
\hline & OTHER & 0 & 0 & 0 & 0 \\
\hline \multirow{2}{*}{$\begin{array}{l}\text { HAS THE DECISION BEEN APPROVED BY THE } \\
\text { CONSULTANT IF THEY WERE NOT THE INITIAL } \\
\text { DECIDER }\end{array}$} & YES & $N / R$ & & 8 & $88.89 \%$ \\
\hline & NO & $\mathrm{N} / \mathrm{R}$ & & 1 & $11.11 \%$ \\
\hline \multirow[t]{4}{*}{$\begin{array}{l}\text { HAS THE PATEINT AND FAMILY BEING INVOLVED } \\
\text { IN THEIR RESUSCITATION DECISION? }\end{array}$} & $\begin{array}{l}\text { NONE } \\
\text { INVOLVED }\end{array}$ & 1 & $25 \%$ & 2 & $14.29 \%$ \\
\hline & $\begin{array}{l}\text { PATIENT } \\
\text { ONLY }\end{array}$ & 0 & 0 & 0 & 0 \\
\hline & FAMILY ONLY & 3 & $75 \%$ & 12 & $85.72 \%$ \\
\hline & $\begin{array}{l}\text { BOTH } \\
\text { INVOLVED }\end{array}$ & 0 & 0 & 0 & 0 \\
\hline \multirow{2}{*}{$\begin{array}{l}\text { IF EITHER/ BOTH PARTY HAS NOT BEING } \\
\text { INVOLVED, IS THE REASON FOR THAT CLEARLY } \\
\text { DOCUMENTED? }\end{array}$} & YES & 1 & $25 \%$ & 11 & $78.57 \%$ \\
\hline & NO & 3 & $75 \%$ & 3 & $21.43 \%$ \\
\hline \multirow[t]{2}{*}{ HAS THE DECISION BEING REVIEWED? } & YES & 0 & 0 & 0 & 0 \\
\hline & NO & 0 & 0 & 0 & 0 \\
\hline
\end{tabular}

In patients who died during their last admission, $8 / 40(20 \%)$ in the pre-intervention group and 8/38 (21.05\%) in the post- intervention group had an ICU admission during their last admission. Interestingly, all the patients who had a DNACPR decision in the pre-intervention group $4 / 4(100 \%)$, but only $6 / 14(42.85 \%)$ had an ICU admission. Only 2/40 (5\%) in the pre- intervention and 8/38 $(21.05 \%)$ in the post- intervention group had clear documentation about escalation of care apart from the resuscitation plan in case of cardiopulmonary arrest such as IV antibiotics, ICU admissions, intubation, NIV, dialysis etc. When such an escalation plan was found in the post-intervention group, the information was documented in the goals-ofcare form in most cases (75\%). None of the decisions/ actions taken at end of life were subjected to legal procedures. 
Table 3

Resuscitation decisions suggested by the junior staff and their comparison to the expert deicsion

\begin{tabular}{|c|c|c|c|c|c|c|c|}
\hline & & \multicolumn{3}{|c|}{ Pre- intervention period } & \multicolumn{3}{|c|}{ Post- intervention period } \\
\hline & & $\begin{array}{l}\text { For } \\
\text { CPR }\end{array}$ & $\begin{array}{l}\text { Not for } \\
\text { CPR }\end{array}$ & Undetermined & $\begin{array}{l}\text { For } \\
\text { CPR }\end{array}$ & $\begin{array}{l}\text { Not for } \\
\text { CPR }\end{array}$ & Undeterminec \\
\hline Expert & & $6(15 \%)$ & $\begin{array}{l}33 \\
(82.5 \%)\end{array}$ & 0 & 5 & $\begin{array}{l}33 \\
(86.8 \%)\end{array}$ & 0 \\
\hline Interns & & $\begin{array}{l}27 \\
(67.5 \%)\end{array}$ & $\begin{array}{l}5 \\
(12.5 \%)\end{array}$ & $8(20 \%)$ & $\begin{array}{l}13 \\
(34.2 \%)\end{array}$ & $\begin{array}{l}18 \\
(47.4 \%)\end{array}$ & $7(18.4 \%)$ \\
\hline Registrars & & $\begin{array}{l}18 \\
(45 \%)\end{array}$ & $\begin{array}{l}12 \\
(30 \%)\end{array}$ & $10(25 \%)$ & $\begin{array}{l}8 \\
(21.1 \%)\end{array}$ & $\begin{array}{l}22 \\
(57.8 \%)\end{array}$ & $8(21.05 \%)$ \\
\hline $\begin{array}{l}\text { No. of } \\
\text { junior } \\
\text { staff } \\
\text { decisions }\end{array}$ & Interns & $\begin{array}{l}6 \\
(15 \%)\end{array}$ & $\begin{array}{l}5 \\
(12.5 \%)\end{array}$ & 0 & $\begin{array}{l}5 \\
(13.1 \%)\end{array}$ & $\begin{array}{l}17 \\
(44.7 \%)\end{array}$ & 0 \\
\hline $\begin{array}{l}\text { agreement } \\
\text { with } \\
\text { expert } \\
\text { decision }\end{array}$ & Registrars & $6(15 \%)$ & $\begin{array}{l}12 \\
(30 \%)\end{array}$ & 0 & $\begin{array}{l}5 \\
(13.1 \%)\end{array}$ & $\begin{array}{l}22 \\
(57.8 \%)\end{array}$ & 0 \\
\hline
\end{tabular}

Written consent (consent form attached- Annexure 3) was obtained from all the doctors who contributed with their professional opinion regarding the advance resuscitation decision. We did not encounter any refusals from doctors.

\section{Discussion}

This audit was done to interrogate the current practice regarding advance resuscitation decisions in the public hospital setting in Sri Lanka, with a view to explore the measures that can improve this practice. The comparison of results between the pre- intervention and post- intervention groups clearly demonstrates that simple measures like improving the knowledge of junior doctors about advance resuscitation decisions and introduction of a pre-printed form to document these decisions can significantly improve patient outcomes in end-of-life care.

The baseline characteristics of the two patient groups on presentation to the hospital are not very (Table 1) different from each other. As highlighted above, the fact that none of the patients in either group had a prior resuscitation decision (carried over from previous admissions/ encounters with health care professionals) or an advance health directive on admission reflects the lack of knowledge about such decisions among both the public as well as health care professionals treating them. The situation is made worse by lack of specific laws to empower advance health directives or to appoint guardians for healthrelated matters when people lack capacity. 
Increase in the number of documented DNACPR decisions in the post- intervention group compared to the pre- intervention group must have been driven by several factors.

1. Improved knowledge in junior doctors within the team

2. Increased consciousness about the concept in senior doctors with an adequate knowledge

3. Better documentation of the decisions taken

In our experience, it is a common misconception among junior doctors that all patients with cardiorespiratory arrest should be resuscitated as a legal requirement.

Many patients were unsuccessfully resuscitated before their death. The number of unsuccessful CPR attempts reduced significantly in the post- intervention period compared to the pre- intervention period. The unsuccessful resuscitations which happened even when there was a clearly documented decision not to resuscitate reflects a failure in communication between the doctors. This could have happened for several reasons.

1. Incomplete shift handovers

2. Not respecting documented decisions

3. Not reading previous entries in patient notes

4. Not understanding the documented concept

5. Pressure from patient's family to do 'everything'

In the pre-intervention period, all the documented DNACPR decisions have been initiated by the consultants. This is a positive approach as the team leader. In contrast, most of the decisions in the postintervention period have been taken by the senior Registrars and later approved by the consultants. This could be thought as a more encouraging approach to inculcate the concept among trainees. There is one decision that has not been approved by the consultant. Such moves could contribute to poor patient outcomes and trainees should always discuss these decisions with the most senior and the most experienced member of the treating team.

Involvement of the family without the patient even when the patient has capacity to make decisions is seen in both pre- and post- intervention groups. On the one hand, this reflects the doctors' acceptance of the concept of 'familial dominance' seen in Asian culture, but on the other hand their failure to respect patient autonomy $(12)(10)$.

We identified that documentation is suboptimal regarding clinical decisions at multiple stages of process. Introduction of a standardized goals-of-care form has most probably contributed to the improved documentation in the post-intervention group in combination with other measures. Medical practitioners should be encouraged properly document their clinical decisions for the safety of both the patients and medical profession.

Furthermore, we noticed that many of the patients who received a DNACPR decision had an ICU admission. While this shows prudent decision making in a critical care setting, it may again reflect failure of early 
decision making. Some patients had been appropriately stepped down from the ICU to a more palliative treatment approach when further escalation of care was decided not to be in the best interest of the patient.

Considering the above findings of suboptimal practice and documentation of advance resuscitation decision, we can conclude that the lack of legal actions taken against resuscitation practice, is probably a reflection of failure of the system rather than perfect clinical practice. The possible reasons for this failure are,

1. Lack of public knowledge about such procedures

2. Legal procedures consume a lot of money and time

3. Public respect towards doctors as authoritative figures

4. Corruption and malpractices in the legal system itself

There are several limitations in this audit. Firstly, although we assessed the number of co-morbidities on presentation, we did not assess the severity/acuity of the presenting disease/ condition, which has a huge impact on the resuscitation decision as well as escalation of patient care (Eg; APACHE, SAPS, SOFA, MODS)(13)(14). Secondly, the audit was limited to two general medical wards in the National Hospital of Sri Lanka, which is the main tertiary care reference center in the country. Therefore, the results cannot be generalized to other settings of care. Thirdly, the follow up was limited to two months, which is inadequate to assess sustainability of our interventions.

For the future, we suggest that Sri Lanka needs more larger scale clinical audits to find out existing practice about end-of-life care across all tiers of health care. More interventional studies are required to experiment the appropriate treatments and more effective methods to improve documentation of clinical decisions (Eg; to evaluate the performance of a standardized form to document resuscitation decisions at national level) in end-of-life care.

Within the constraints of our audit, we recommend that precise documentation of clinical decisions is paramount to success in end-of-life care. Importantly, when a decision is made, this should be reviewed regularly during the index admission and during subsequent admissions. The legal framework regarding resuscitation decisions should be revisited and revised. Appropriate measures should be taken to increase public awareness about the appropriate use of CPR and other measures of escalation of care. Patients/ public should be encouraged to make their own resuscitation decisions well in advance of a crisis and there should be appropriate legal provisions to ensure the legal validity and safety of an advance resuscitation plan thus established. Teaching about end-of-life care should be a mandatory component both undergraduate and postgraduate education of doctors. We also propose that doctors should have ongoing training regarding the importance of medical documentation to improve patient outcomes as well as for the safety of the profession against litigation.

\section{Conclusion}


This audit was done to interrogate the current practice of resuscitation decisions and their appropriate documentation in end-of-life care in Sri Lanka. Analysis of data from the pre-intervention period demonstrate the suboptimal advance decision-making and documentation of resuscitation decisions. Results from the post- intervention period demonstrate that our interventions to improve the knowledge of junior medical officers about appropriate use of advance resuscitation decisions and introduction of a preprinted form to document resuscitation preference on admission clearly improve the outcomes in end-of life care.

\section{Declarations}

Ethics approval and consent to participate

Ethical approval was obtained from the Ethics Review Committee of Faculty of Medicine, University of Colombo (EC-21-025). All methods were carried out in accordance with the Declaration of Helsinki. Informed written consent was obtained from all the junior doctors who provided their professional opinion about the resuscitation decisions

CONSENT FOR PUBLICATION

Not relevant.

AVAILABILITY OF DATA AND MATERIALS

The datasets used and/or analysed during the current study are available from the corresponding author on reasonable request

COMPETING INTERESTS

Authors declare no financial or non-financial competing interests

FUNDING

This study was not funded by any external agencies/ individuals.

AUTHORS' CONTRIBUTION

Authors contributed equally to writing the audit protocol, data collection and analysis preparing the manuscript for publication.

ACKNOWLEDGEMENT

Not applicable.

\section{References}


1. Kouwenhoven WB, Jude JR, Knickerbocker GG. Closed-chest cardiac massage. J Am Med Assoc [Internet]. 1960 Jul 9 [cited 2020 Aug 24];173(10):1064-7. Available from:

https://pubmed.ncbi.nlm.nih.gov/14411374/

2. Andersen LW, Holmberg MJ, Berg KM, Donnino MW, Granfeldt A. In-Hospital Cardiac Arrest: A Review [Internet]. Vol. 321, JAMA - Journal of the American Medical Association. American Medical Association; 2019 [cited 2020 Aug 25]. p. 1200-10. Available from: /pmc/articles/PMC6482460/? report $=$ abstract

3. Girotra S, Nallamothu BK, Spertus JA, Li Y, Krumholz HM, Chan PS. Trends in survival after in-hospital cardiac arrest. N Engl J Med. 2012 Nov 15;367(20):1912-20.

4. Akdeniz M, Yardımcı B, Kavukcu E. Ethical considerations at the end-of-life care. SAGE Open Med [Internet]. 2021 Jan [cited 2021 Jun 14];9:205031212110009. Available from: /pmc/articles/PMC7958189/

5. Moulaert VRMP, Wachelder EM, Verbunt JA, Derick T W, Van Heugten CM. Determinants of quality of life in survivors of cardiac arrest. J Rehabil Med [Internet]. 2010 Jun [cited 2020 Sep 7];42(6):553-8. Available from: https://pubmed.ncbi.nlm.nih.gov/20549160/

6. Rabkin MT, Gillerman G, Rice NR. Orders Not to Resuscitate. N Engl J Med [Internet]. 1976 Aug 12 [cited 2018 Oct 26];295(7):364-6. Available from: http://www.nejm.org/doi/abs/10.1056/NEJM197608122950705

7. GHO | Key Country Indicators | Sri Lanka - key indicators [Internet]. [cited 2020 Aug 26]. Available from: https://apps.who.int/gho/data/node.cco.ki-LKA?lang=en

8. Beane A, Ambepitiyawaduge PDS, Thilakasiri K, Stephens T, Padeniya A, Athapattu P, et al. Practices and Perspectives in Cardiopulmonary Resuscitation Attempts and the Use of Do Not Attempt Resuscitation Orders: A Cross-sectional Survey in Sri Lanka. Indian J Crit Care Med [Internet]. 2017 Dec [cited 2018 Oct 27];21(12):865-8. Available from: http://www.ncbi.nlm.nih.gov/pubmed/29307970

9. Pinto M, Varun R, M P B Wanasinghe WM, K Jayasinghearachchi TM, T A Herath HM, R Kumarasiri P $V$, et al. A cross-sectional study of knowledge and attitudes of medical professionals towards end-oflife decisions in teaching hospitals of Kandy District (Sri Lanka). Vol. 17, PAIN \& INTENSIVE CARE.

10. Dodd A, De Silva V, Fritz Z. A qualitative study of practice, culture and education of doctors in Sri Lanka regarding 'do not attempt cardiopulmonary resuscitation' decisions and disclosure. Clin Ethics [Internet]. 2018 Mar 31 [cited 2018 Oct 30];13(1):17-25. Available from: http://journals.sagepub.com/doi/10.1177/1477750917738106

11. Nolan J. Decisions relating to cardiopulmonary resuscitation. Notfall + Rettungsmedizin. 2014;11(4):229-31.

12. Ho ZJM, Radha Krishna LK, Yee CPA. Chinese Familial Tradition and Western Influence: A Case Study in Singapore on Decision Making at the End of Life. J Pain Symptom Manage [Internet]. 2010 Dec [cited 2018 Nov 24];40(6):932-7. Available from: http://www.ncbi.nIm.nih.gov/pubmed/21145471

13. Marshall JC, Cook DJ, Christou N V., Bernard GR, Sprung CL, Sibbald WJ. Multiple organ dysfunction score: A reliable descriptor of a complex clinical outcome [Internet]. Vol. 23, Critical Care Medicine. Crit 
Care Med; 1995 [cited 2020 Aug 9]. p. 1638-52. Available from:

https://pubmed.ncbi.nlm.nih.gov/7587228/

14. Vincent JL, Moreno R, Takala J, Willatts S, De Mendonça A, Bruining H, et al. The SOFA (Sepsis-related Organ Failure Assessment) score to describe organ dysfunction/failure. Intensive Care Med [Internet]. 1996 [cited 2020 Aug 9];22(7):707-10. Available from: https://pubmed.ncbi.nlm.nih.gov/8844239/ 